\title{
Occurrence of TEC fluctuations and GPS positioning errors at different longitudes during auroral disturbances
}

\author{
Shagimuratov I.I. ${ }^{1}$, Chernouss S.A. ${ }^{2}$, Despirak I.V. ${ }^{2}$, Filatov M.V. ${ }^{2}$, Efishov I.I. ${ }^{1}$, \\ Tepenitsyna N.Yu. ${ }^{1}$ \\ ${ }^{1}$ WD IZMIRAN, Kaliningrad, Russia; \\ ${ }^{2}$ Polar Geophysical Institute, Apatity, Russia \\ E mail (despirak@gmail.com).
}

Accepted : 23 April 2018

\begin{abstract}
In this work we analyzed the occurrence of the GPS TEC fluctuations associated with auroral disturbances during the storm on January 7, 2015. The impact of the disturbance on GPS precise positioning were considered. For this purpose, we used the observations of GPS stations located at the European, American and Asian sectors. The auroral activity was determined by data of the IMAGE magnetometers network. The rate of TEC (ROT) used as measure of the TEC fluctuation activity. The intensity fluctuations evaluated by index ROTI. The behavior of fluctuations on different longitudes is very similar. The comparison of substorm activity and the time evolution of the TEC fluctuations showed good consistency. The maximum intensity of TEC fluctuations was observed simultaneously (at the same UT time) over GPS stations which were located at different longitudes. In our work an impact of the geomagnetic disturbances on the Precise Point Positioning (PPP) errors was analyzed. The positioning errors were determined using the GIPSY-OASIS software (APS-NASA). The 3D position errors (P3D) reached the large values (more than $10 \mathrm{~m}$ ) during storm, while they did not exceed $30 \mathrm{~cm}$ during quiet geomagnetic conditions. Our analysis showed the close relation between ROTI and the positioning errors. The positioning errors increased rapidly with increasing of ROTI.
\end{abstract}

(c) 2018 BBSCS RN SWS. All rights reserved

Keywords: auroral ionosphere, geomagnetic storm, irregularities, GPS.

\section{Introduction}

Total electron content fluctuations at high latitudes are caused by presence of the irregularities of different scale in the ionosphere (Kintner et al., 2007). There are a lot of works devoted to this problem (Aarons, 1997; Spogli et al., 2009; Shagimuratov et al., 2015a; Prikryl et al., 2015a; Cherniak and Zakherenkova, 2015; Prikryl et al., 2016). The occurrence of the scintillation at high latitudes is related to the patches in the auroral oval, cusp, and polar-cap. These patches were associated with the formation of small-scale plasma structures which occurred due to particle precipitation or plasma instabilities (Weber et al., 1986; Kersley et al., 1995; Aarons, 1997; Krankowski et al., 2006; Spogli et al., 2009). It was shown that the phase scintillation occurs more often than the amplitude scintillation at high latitudes. The scintillations are more common in the auroral oval during geomagnetic disturbed conditions and were registered close to the noon and the midnight (Spogli et al., 2009; Moen et al., 2013). Some authors found that the strong correlations between the GPS phase scintillation and fluctuations of optical auroral emissions is occurred during investigation of the auroral arcs (Kinrade et al., 2013; Smith et al., 2008). In the auroral ionosphere the increasing of the fluctuations intensity followed after the auroral activity was observed (Aarons, 1997; Shagimuratov et al., 2015). The GPS scintillation was observed during events of energetic particle precipitation, substorms and pseudo-breakups in the auroral oval (Skone et al., 2008; Kinrade et al., 2013; Prikryl et al., 2013a, 2013b) and it was correlated with ground magnetic field disturbances (Ghoddousi-Fard et al., 2015).

The scintillations over Europe in period 2012 were presented in the work of Jacobsen and Dähnn (2014) and the same for the storm of 17 March 2015 was presented by Jacobsen and Andalsvik (2016).
Strong TEC fluctuations can complicate the phase ambiguity resolution and increase the number of the undetected and uncorrected cycle slips and the loss of the signal lock in the GPS navigation and positioning errors (Skone and de Jong, 2000; Kintner et al., 2007; Chernouss, Kalitenkov, 2011; Astafyeva et al., 2014; Jacobsen and Dähnn, 2014).

In this paper the occurrence of the TEC fluctuations and positioning errors at European, American and Asia longitudes during the geomagnetic storm on January 07, 2015 is presented. The direct comparison between the intensity of fluctuations and the positioning errors at auroral stations make it clear that the accuracy precise of the point positioning at high latitudes is worse during substorms.

\section{Data and Method}

In this analysis we used the standard GPS observations provided by the IGS network. The TEC measurements with $30 \mathrm{sec}$ - interval resolution during individual satellite passes served as raw data. Rate of TEC (ROT) in the unit of TECU/min used as a measure of the fluctuations activity, where

$1 \mathrm{TECU}=10^{16}$ electron $/ \mathrm{m}^{2}$ with $1 \mathrm{~min}$ interval resolution was applied. In the Table 1 the stations, which were used for analysis of occurrence of the TEC fluctuations at different longitudes are presented.

ROT are usually used to estimate TEC fluctuations (Krankowski et al. 2006):

ROT $=9.53\left(\left(\Phi_{1}-\Phi_{2}\right)_{\mathrm{tj}}-\left(\Phi_{1}-\Phi_{2}\right)_{\mathrm{ti}}\right)$

where $\Delta t=\mathrm{tj}-\mathrm{ti}=1 \mathrm{~min}, \Phi_{1}$ and $\Phi_{2}[\mathrm{~m}]$ denote the measured phase of differential carrier observed at L1 and L2. A scaling factor converts the differential ionospheric delay to units of electrons $/ \mathrm{m}^{2}$. Index ROTI calculated with $10 \mathrm{~min}$ interval resolution used as a measure of the intensity of fluctuation (Pi et al. 1997; Jacobsen 2014). Index ROTI was 


\section{$R O T I=\sqrt{\left\langle R O T^{2}\right\rangle-\langle R O T\rangle^{2}}$}

Geomagnetic data were downloaded from the website wdc.kugi.kyoto-u.ac.jp. Geomagnetic conditions during storm on January 7, 2015 are presented in Fig. 1.

The storm on January 7, 2015 was the moderate one. The maximal value of the Dst index was -100 nT, $\mathrm{K}_{\mathrm{p}}$ index value was about 6. The maximal auroral activity was observed in the period of 09-12 UT, when the main phase of the storm was developed. Previous analysis of the storm pointed out that the maximal intensity of the TEC fluctuations is occurred during substorm activity (Shagimuratov et al., 2015b). The magnetometers data of the Scandinavian chain was used as indicator of the substorm activity (Fig. 2). The magnetometers network includes the stations located in auroral, subauroral and mid-latitude zones. The intensity of the magnetic bay is decreased from the North to the South. The strongest magnetic variations were registered after 09 UT, when a weak bay of magnetic disturbances was observed even at $\sim 54^{\circ} \mathrm{N}$.

The Precise Point Positioning errors were determined using the GIPSY-OASIS software (apps.gdgps.net).

Table 1. Geographic and corrected geomagnetic

coordinates of stations which were used for analysis of the occurrence of TEC fluctuations.

\begin{tabular}{|l|c|c|c|c|}
\hline \multirow{2}{*}{ stations } & \multicolumn{2}{|c|}{$\begin{array}{c}\text { Geographic } \\
\text { coordinates }\end{array}$} & \multicolumn{2}{c|}{$\begin{array}{c}\text { Corrected } \\
\text { geomagnetic } \\
\text { coordinates }\end{array}$} \\
\cline { 2 - 5 } & latitude & longitude & latitude & Longitude \\
\hline SG27 & 71.2 & -156.4 & 70.0 & 251.3 \\
\hline TROM & 69.4 & 18.6 & 66.3 & 103.6 \\
\hline TIXI & 71.4 & 128.5 & 65.4 & 196.8 \\
\hline
\end{tabular}

\section{Observations and discussion}

Our purpose is to find an impact of auroral disturbances to parameters of GPS signals on passing their through the high latitude ionosphere. The auroral disturbances abruptly corrupting the performance of the positioning systems. The analysis concerns occurrence of phase fluctuations over auroral stations located at European, American and Asian sectors during strong auroral disturbance of January 7, 2015. We select stations located at latitude near of $70^{\circ} \mathrm{N}$. (Table 1) and analyzed the temporal occurrence of the TEC fluctuations using the standard $30 \mathrm{sec}$ GPS phase measurements. The fluctuation activity was evaluated by ROT. On this base we formed the picture which demonstrates the behavior of ROT over station for all satellite passes in 24-hour interval. (Fig. 3).

The appearance of TEC fluctuations demonstrated a very similar behavior in all sectors. The maximal intensity of fluctuations was registered in the period $09 \div 16$ UT on January 7, 2015, when auroral disturbance was developed.

The intensity of TEC fluctuations was evaluated by the index of ROTI, which was calculated with 10 min resolution. The indices computed only from the observations, for which elevation angles are higher than $20^{\circ}$. In order to account of the varying geometrical effects, the indices are projected on the vertical direction. We use a height of $450 \mathrm{~km}$ when we doing mapping the slant of TEC to vertical TEC in the

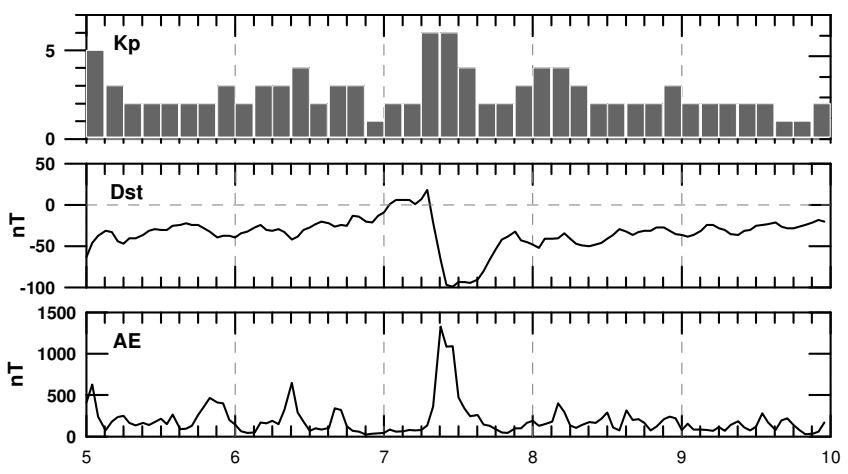

Figure 1. $\mathrm{K}_{\mathrm{P}}, \mathrm{D}_{\mathrm{ST}}$ and $\mathrm{AE}$ geomagnetic indexes for period of January $5-9,2015$.

ionosphere. A mapping function was applied at the ionospheric pierce point (IPP) by the assuming of model of the ionosphere as thin shell. The ionospheric pierce point is determined as the point, where the receiver - satellite ray intersect the ionospheric shell at the height of $450 \mathrm{~km}$. The detail outline of the algorithm to calculating of IPP is presented by Shagimuratov et al. (2013). The latitudinal-temporal behavior of ROTI was presented in the coordinates of Geographic Latitude - Universal Time (UT).

Spatial-temporal occurrence intensity of TEC fluctuations at American (SG27 station), European (TROM), Asian (TIXI) sectors are presented in Fig. 3 (circles). The fluctuations occurrence on the different longitudes demonstrated very similar behavior. Rather good coherence exists between the time evolution of the substorm and the intensity of TEC fluctuations. The maximal intensity fluctuations (effect) was occurred near 12 UT at all sectors. The fluctuations intensity is less in the Europe sector that in the America and Asia sectors. Perhaps, it is associated with the dependence on the local time (LT) of the occurrence of TEC fluctuations in the auroral ionosphere. The fluctuations used to occur in the auroral oval and were observed close to the local midnight. The auroral activity has occurred at daytime in Europe, while in America and Asia regions were at night. In the daytime the TEC fluctuations at the auroral and subauroral aria is ordinary weak.

\section{TEC fluctuations and GPS positioning errors}

Now there are a number of software packages, which are used for PPP estimations. A detailed discussion of the PPP method can be found in the paper by Kouba and Heroux (2001). Usually the ionospheric-free combinations of dual-frequency GPS pseudorange and carrier-phase observations are used to eliminate first order ionospheric delays in measurements. As it shown $\mathrm{Pi}$ et al. (2017) the positioning error can increase significantly, what is caused by phase data degradation due to scintillations. The accuracy of GPS positioning is strongly influenced by ionospheric fluctuations (scintillations), which increase during geomagnetic disturbances. The intensive fluctuations sometimes lead to phase cycle slips and signal loss lock. For GPS, the L2 signal (1227.6 $\mathrm{MHz}$ ) is generally more affected and losses of signal in the L2. Losses of signal can cause problems when applying the ionosphere free combination (ion-free) that is generally used in PPP. As it was shown by Marques et al. (2018) number cycle slips and loss lock 


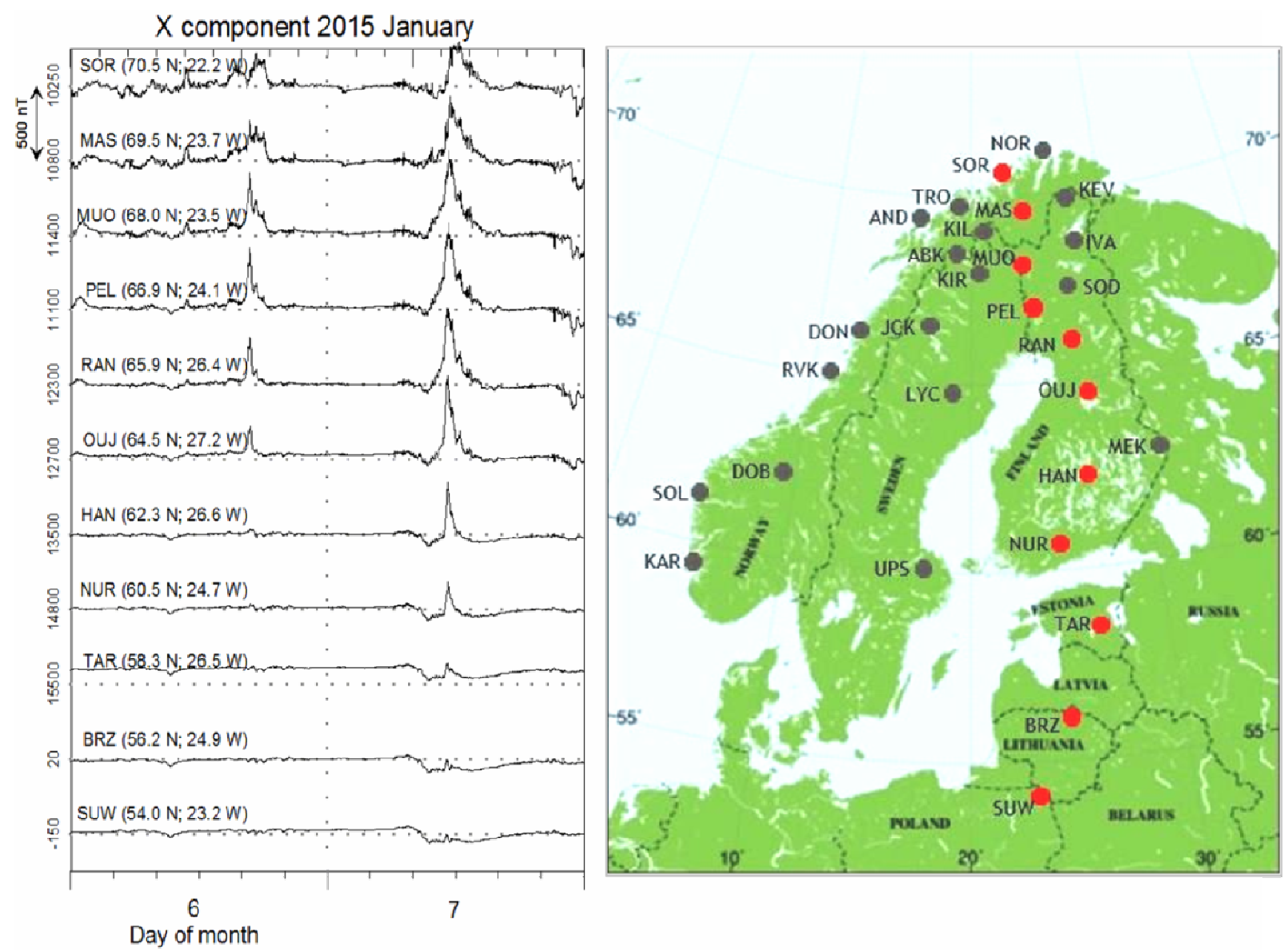

Figure 2. The variations of the X-component of geomagnetic field at different stations on January 6- 7, 2015 (left panel) and the map of Scandinavian network stations (right panel).
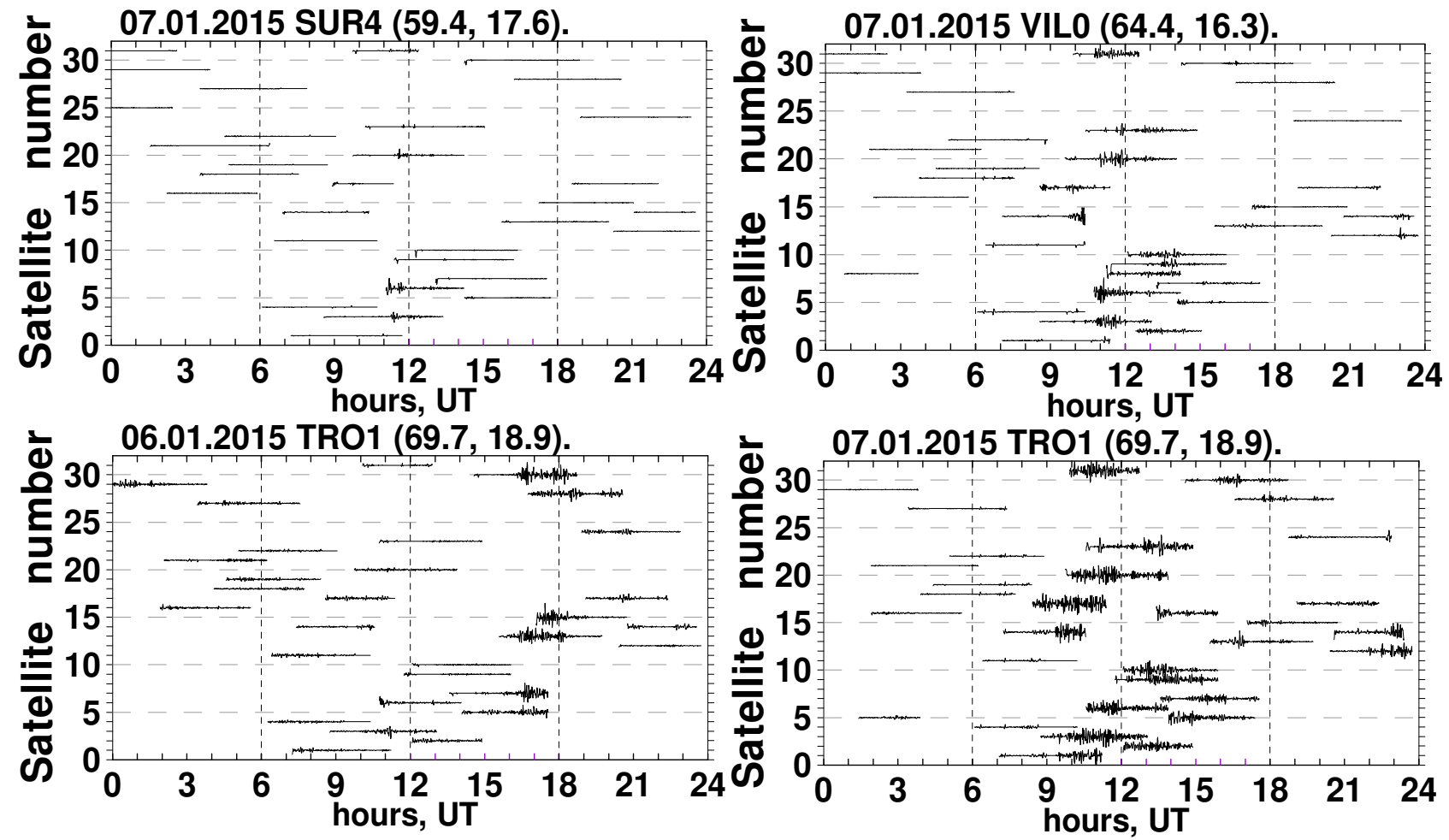

Figure 3. Development of TEC fluctuations (ROT) at mid-latitude, subauroral and auroral stations on January 6 - 7, 2015. 

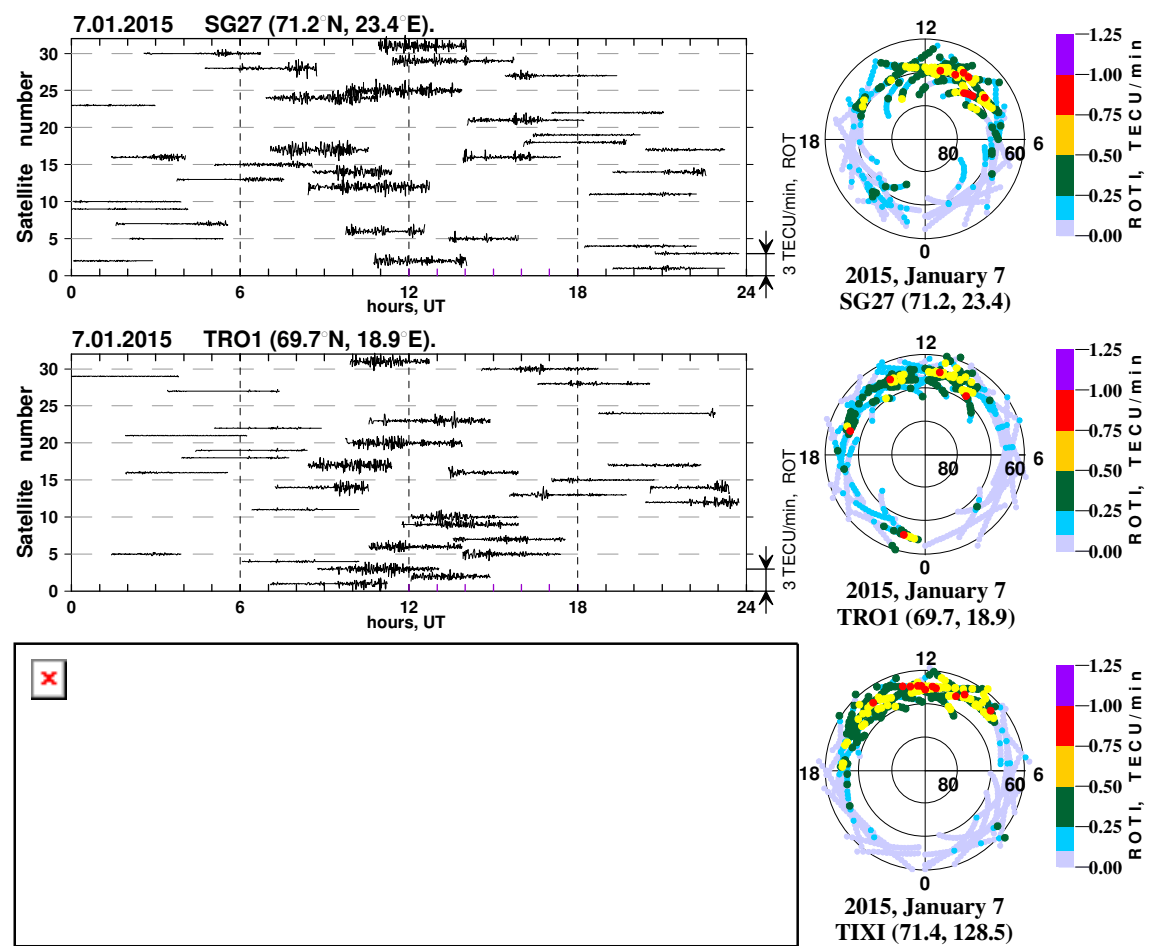

Figure 4. Development of TEC fluctuations all satellite passes over 24-hour interval and their intensity (circles) for auroral zone stations located at different longitudes

Table 2. Parameters of the models used for the GIPSY PPP solution (taken from Jacobsen and Dahnn (2014)

\begin{tabular}{|l|l|}
\hline GIPSY version & 6.3 \\
\hline Reference frame & IGb08 \\
\hline $\begin{array}{l}\text { Elevation } \\
\text { angle cut off }\end{array}$ & 70 \\
\hline $\begin{array}{l}\text { Elevation } \\
\text { dependent } \\
\text { weighting }\end{array}$ & Yes ( $\sigma=1 / \sqrt{\sin (\text { elevation) }}$ ) \\
\hline $\begin{array}{l}\text { Antenna phase } \\
\text { centre (receivers, } \\
\text { transmitters) }\end{array}$ & $\begin{array}{l}\text { Absolute based on IGS standard } \\
\text { (igs08_1816.atx) }\end{array}$ \\
\hline $\begin{array}{l}\text { Troposphere } \\
\text { mapping function }\end{array}$ & VMF1 \\
\hline $\begin{array}{l}\text { Tropospheric } \\
\text { nominal values }\end{array}$ & $\begin{array}{l}\text { Wet and dry nominal values based } \\
\text { on VMF1 grid model }\end{array}$ \\
\hline $\begin{array}{l}\text { 2nd-order } \\
\text { ionosphere model }\end{array}$ & Based on IONEX files \\
\hline Ocean loading & FES2004 \\
\hline $\begin{array}{l}\text { Ocean pole } \\
\text { tide model }\end{array}$ & Yes \\
\hline Ambiguity resolution & Yes \\
\hline
\end{tabular}

signals can sharp increase jumps in the positioning errors under the intensive fluctuations. In particular, kinematic PPP trajectories are strongly influenced by the geometry of the satellite constellation being tracked. The effect of the geometry can be measured by the Dilution of Precision (DOP) parameter, which is strongly related with the number and spatial distribution of satellites. Kinematic positioning is degraded in general, when a small number of satellites is available, which frequently occurs in urban trajectories or under severe atmospheric conditions, as an example, under ionospheric scintillation effects. When there are simultaneously cycle slips, signal loss lock and non optimal geometry of the satellite constellation positioning errors can essentially increase.
We analyzed the link between the intensity of TEC fluctuations (index ROTI) and Precise Point Positioning errors using the GIPSY software of the NASA Jet Propulsion Laboratory, in the kinematic mode (apps.gdgps.net). The Precise Point Positioning is the processing strategy of the single receiver for GNSS observations that enables the efficient computation of the high-quality coordinates, utilizing undifferenced dual-frequency code and the phase observations (RINEX files) by using precise satellite orbit and the products of the clock data. The important information about the models and the parameters used in the PPP solution are listed in Table 2.

We calculated the coordinates for TRO1 (Europe), SG27 (America) and TIXI (Asia) stations for the storm day on January 7,2015 . The 3D position error $\left(P_{3 D}\right)$ was defined as the offset of the detrended coordinate from its median value $\left(x_{0}, y_{0}, z_{0}\right)$ and was calculated for each epoch (Jacobsen and Dähnn 2014):

$$
P_{3 D}(i)=\sqrt{\left(x(i)-x_{0}\right)^{2}+\left(y(i)-y_{0}\right)^{2}+\left(z(i)-z_{0}\right)^{2}}
$$

As the median value $\left(x_{0}, y_{0}, z_{0}\right)$ we used the coordinate calculated on 24-hour interval for the previous day of the storm in static mode. The 3D position errors were computed with 5-min interval.

The high correlation between the positioning errors and the ROTI for 2012 at $59^{\circ}-79^{\circ} \mathrm{N}$ latitudes was found by Jacobsen and Dähnn (2014), as well for European sector it was found in the case of the study of the geomagnetic storm on March 17, 2015. The positioning errors increase exponentially with the increasing of the ROTI (Jacobsen and Schäfer, 2012). We analyzed the relationship between the ROTI and the 3D position errors for the stations located on different longitudes in the auroral zone. The satellites observations with the elevations above $20^{\circ}$ have been included in the 
calculating of the index ROTI. In the calculation of the 3D position errors we used also the same procedure.

Fig. 4 shows the temporal variations ROTI during the storm and the 3D positioning errors at TRO1, SG27 and TIXI stations. On the Fig. 4 the variability of the ROTI values calculated for all visible passes of the GPS satellites shows by dots for the selected stations and for every epoch. It is seen that exists the very good similarity in behaviors of the ROTI and the positioning errors, the increase of ROTI values followed by increase of positioning error at three stations. Usually, the GPS positioning requires a minimum of four simultaneously tracked satellites with a good geometry. If the irregularities of electron density cover a large area above the receiver, there is the high probability that the receiver can lose more than one satellite signal simultaneously. Maximal number loss lock L2 signals occurred at a time when fluctuation activity was high. Simultaneous loss of a significant number of the satellite signals discontinues the GNSS navigation or degrades the navigation accuracy (Cherniak et al., 2014). Perhaps, a similar situation was realized over the SG27 station around 09:45 UT. The positioning errors reach more than $20 \mathrm{~m}$ in this time period. The errors were 5.7 and 3.3 meters at 09:40 UT and 09:50 UT respectively. At the TIXI station the background of the position errors is higher than at the TRO1 and SG27 stations. It can be associated a multipath. Fig. 5 demonstrated the nonlinear character of position errors with the respect to the ROTI changes. Thus, the small ROTI value, registered near on 03 UT at TRO1 station, caused the noticeable eruption in 3D error. However, this effect does not observe at the TIXI station at the same time.

It is seen that exists a very good similarity of the behaviors in the ROTI and positioning errors, the increase of ROTI values is followed by the increase of the positioning error at three stations. The maximal errors were registered at the SG27 station, the positioning errors reach more than $20 \mathrm{~m}$. As seen from figure 4, the nonlinear character of position errors with respect to the ROTI changes was observed. Thus, the small ROTI value, which was observed near 03 UT at the TRO1 station, caused the noticeable eruption in 3D error. However, this effect does not occur at the TIXI station at the same time. In the Fig. 6 the correlation between the ROTI and positioning errors is presented. For constructing the Fig. 6 we used data of three stations because the behavior of 3D errors in depend of the ROTI is similar. In cases of the fluctuations absence the background errors differ on the stations, we superposed the background values with one another for these stations. The errors are randomly for small intensity. The 3D position errors increase exponentially with increasing of the ROTI. The correlation coefficient reached the values about 0.53 . In case of weak small values of the TEC fluctuations, the position errors define by the threshold of errors over station.
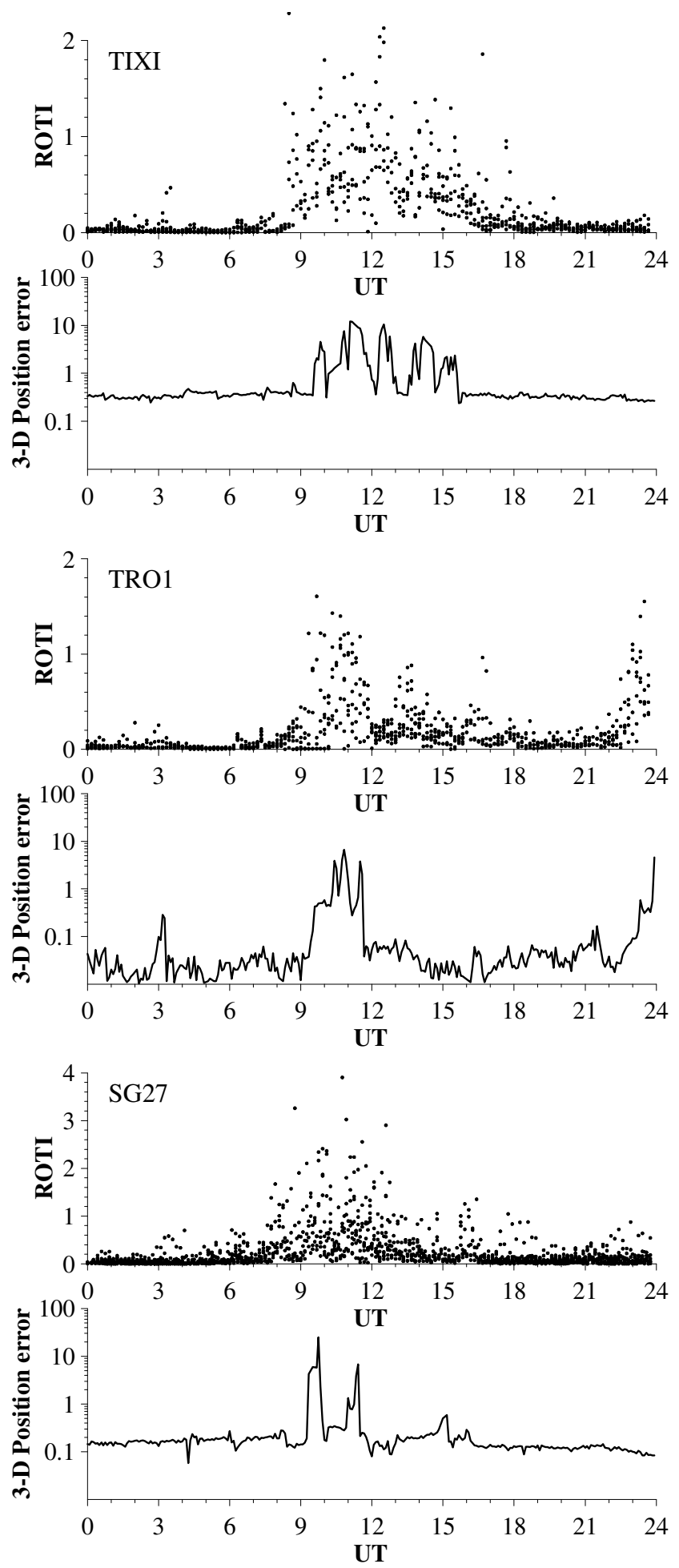

Figure 5. Time variations of TEC fluctuations (index ROTI) and 3D positioning errors for stations on different longitudes during the storm day on January 7, 2015

\section{Summary}

We carried the analysis an occurrence of the GPS TEC fluctuations associated with the auroral disturbances and studied the impact of these disturbances on the GPS precise positioning errors at different longitudinal sectors during the storm on January 7, 2015. The maximal auroral activity was observed on 09-12 UT. It was occurred during daytime for Europe sector and during nighttime for Alaska and Asia sectors. The TEC fluctuations were more weak in Europe sector than in American and Asian sectors. We 
used the index ROTI as the measure of TEC fluctuations intensity. The maximal value of the ROTI was registered over the Asia sectors. It was found that fluctuation activity was observed over all longitude sectors simultaneously, at the same UT time (UT effect). We calculated errors of the 3D positioning with $5 \mathrm{~min}$ interval using the GIPSY-OASIS software. It is shown that the high correlation of the GPS positioning errors with the ROTI index exists. The positioning error increases exponentially with the increasing of ROTI values. In Alaska and Asia regions the positioning errors reached more than $10 \mathrm{~m}$ over the auroral ionosphere during period of the maximal auroral activity, on 09-12 UT. The positioning errors were less than $0.5 \mathrm{~m}$ in quiet geomagnetic periods.

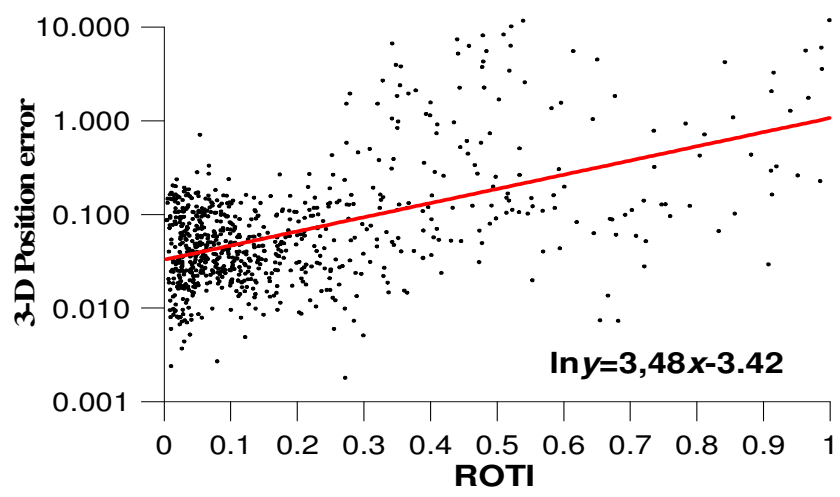

Figure 6 Scatter plot of mean values of the ROTI vs 3D position error. The red line shows an exponential fit to the data.

\section{Acknowledgements}

We are grateful to institutes who maintain the IMAGE Magnetometer Array. This study was supported by grants of RFBR 16-05-01077 and 17-45-510341 p_a, partly supported by Program No 28 of the Presidium of the RAS.

\section{References}

Aarons J. 1997, J. Geophys. Res. 102 (A8), 17219-17231, DOI: 10.1029/97JA01118, 1997.

Astafyeva E., Yasyukevich Y., MaksikovA., Zhivetiev I.: 2014, Space Weather. 12(7), 508.

Cherniak I., Zakharenkova I., Redmon R.J.: 2015, Space Weather. 13, 585-597, doi:10.1002/2015SW001237.

Chernouss S.A., Kalitenkov N.V.: 2011, Remote Sensing. 32(1), 3005.

Ghoddousi-Fard R., Nikitina L., Danskin D., and Prikryl P., 2015, Adv. Space Res. 55(5), 1372-1381, doi:10.1016/j.asr.2014.12.021.

Jacobsen K.S. 2014,. J. Space Weather Space Clim. 4(A33), DOI: $10.1051 / \mathrm{sws} / 2014031$.

Jacobsen K.S., Andalsvik Y.L., 2016, J. Space Weather Space Clim. 6(A9), DOI: $10.1051 / \mathrm{swsc} / 2016004$.

Jacobsen K.S, Dähnn, 2014, J. Sp. Weather Sp. Clim. 4(A27), DOI: $10.1051 / \mathrm{swsc} / 2014024$.

Jacobsen K.S., Schäfer S. 2012, J. Sp. Weather Sp. Clim. 2(A13), DOI:10.1051/swsc/2012013.

Jin Y., Moen J. I. and Miloch W. J., 2015, J. Geophys. Res. [Space Phys.]. 120(10), 9176-9191, DOI: 10.1002/2015JA021449.

Kersley, L., C.D. Russell, and D.L. Rice, Radio Science, 30 (3), DOI: 0.1029/94RS03175, 1995.

Kinrade J., Mitchell C. N., Smith N. D., Ebihara Y., Weatherwax A. T. and Bust G. S., 2013, J. Geophys. Res. Space Physics. 118, 2490-2502, DOI:10.1002/jgra.50214.

Kintner P. M., Ledvina B. M. and Paula E. R. De: 2007, Space Weather. 5, S09003, DOI:10.1029/2006SW000260.

Kouba, J., and P. He'roux, GPS Solutions, 5 (2), 12-28, DOI: 10.1007/PL00012883, 2001.
Krankowski A., Shagimuratov I., Baran L., Efishov I., and Tepenitzyna N., 2006, Adv. Space Res. 38(11), 2601-2609, DOI: $10.1016 /$ j.asr.2005.12.006.

Haroldo Antonio Marques, Heloísa Alves Silva Marques, Marcio Aquino et all., , J. Space Weather Space Clim. 2018, 8, A15, doi.org/10.1051/swsc/2017043.

Meeren C. Van Der, Oksavik K., Lorentzen D.A., Rietveld M.N. and Clausen L.B.N., 2015, J. Geophys. Res. Space Physics, 120, 10,607-10,621, DOI:10.1002/2015JA02181.

Moen J., Oksavik K., Alfonsi L., Daabakk Y., Romano V. and Spogli L.: 2013, J. Space Weather Space Clim. 3(A02), DOI:10.1051/swsc/2013025.

Oksavik K., C. Meeren Van Der, Lorentzen D.A., Baddeley L. J. and Moen J.: 2015, J. Geophys. Res. Space Physics. 120, 91619175, DOI:10.1002/2015JA021528.

Pi X., Manucci A.J., Lindqwister U.J., Ho, C.M.: 1997, Geophys. Res.Lett. 24, 2283.

Pi X, lijima BA, Lu W. 2017. Effects of ionospheric scintillation on GNSS-based positioning., J Inst Navig 64: 3-22, DOI:10.1002/ navi.182.

Prikryl, P., P., Zhang, Y., Ebihara, Y., Ghoddousi-Fard, R., et al.: 2013a, Special Issue of,Ann. Geophys. 56, DOI:10.4401/ag6227.

Prikryl P., Ghoddousi-Fard R., Kunduri B. S. R., Thomas E. G., Coster A. J. et al: 2013, Ann. Geophys. 31, 805-816, doi:10.5194/angeo-31-805-2013b.

Prikryl P., Jayachandran P.T., Chadwick R. and Kelly T.D.: 2015a, Ann. Geophys. 33, 531-545, DOI:10.5194/angeo-33-5312015.

Prikryl P., Ghoddousi-Fard R., Weygand J.M., Viljanen A., Connors M. et al: 2016, Geophys. Res. Space Physics. 121, 10.44810.465, DOI:10.1002/ 2016JA023171.

Shagimuratov I.I., Chernyak, Yu.V., Zakharenkova, I.E., Yakimova, G.A.: Russian Journal of Physical Chemistry B, 2013, Vol. 7, No. 5, pp. 656-662.

Shagimuratov, I., Chernouss, S., Cherniak, lu., Efishov, I., Filatov, M., Tepenitsyna, N.: 2015a, Sun and Geosphere. 11(2), 101.

Shagimuratov, I., Chernouss, S., Cherniak, lu., Zakharenkova, I., Efishov, I., 2015b, Proceedings of the 9th European conference on antennas and propagation, Lisbon, 12-17 April 2015, paper №1570053943.

Skone S., and Jong M. De: 2000, Earth Planets Space. 52, 10671071, DOI:10.1186/BF03352332.

Spogli L., Alfonsi L., Franceschi G. De, Romano V., Aquino M. H. O. and Dodson A., 2009, Ann. Geophys. 27, 3429-3437, DOI: 10.5194

Smith, A.M., Mitchell, C.N., Watson, R.J., Meggs, R.W., Kintner, P.M., K. Kauristie K., Honary, F., 2008. c. Space Weather. 6: S03D01. doi: $10.1029 / 2007$ SW000349.

Sreeja, V. and Aquino M.: 2014, J. Atmos. Sol. Terr. Phys. 120, doi:10.1016/j.jastp.2014.09.003.

Weber E.J., Klobuchar J.A., Buchau J., Carlson H.C., Livingston R.C. et al, 1986, J. Geophys. Res. [Space Phys.]. 91(A11), 12121-12129, 1986, DOI: 10.1029/JA091iA11p12121.

Zumberger J.F., Heflin M.B., Jefferson D.C., Watkins M.M. and Webb F.H., 1997, J. Geophys. Res. [Solid Earth]. 102(B3), 5005-5017, DOI: 10.1029/96JB03860, 1997. 